\title{
Determinants of Mental Health Care Access in a Tribal District of Central India: Findings from a Health Camp
}

\author{
Roshan Sutar ${ }^{1}$ Anuja Lahiri ${ }^{2}$ Sanjeet Diwan ${ }^{1}$ Parmeshwar Satpathy ${ }^{2, \odot ~}$ Abhijit Rozatkar $^{1}$ \\ ${ }^{1}$ Department of Psychiatry, All India Institute of Medical Sciences, \\ Bhopal, India \\ ${ }^{2}$ Department of Community and Family Medicine, All India Institute \\ of Medical Sciences, Bhopal, India

\begin{abstract}
Address for correspondence Roshan Sutar, MBBS, MD, Fellowship in Consultation Liaison Psychiatry, Department of Psychiatry, All India Institute of Medical Sciences, Bhopal, India
\end{abstract} \\ (e-mail: roshidoc@yahoo.co.in).
}

J Neurosci Rural Pract 2021;12:335-342.

\begin{abstract}
Objective Mental health care needs of urban, rural, and tribal regions of India are varied and challenging, which require region-specific approaches. A significant treatment gap calls out for a state-wise introspection of existing service delivery models to cater to the specific mental health needs. In Madhya Pradesh, key findings were noted from a camp conducted in one of the tribal districts. To establish patient-centered services, it is important to understand their mental health care needs.

Materials and Methods A cross-sectional study within a mental health camp was conducted in the east-central tribal district of Madhya Pradesh by using a semi-structured interview.

Statistical Analysis Treatment deficit, pathways to care, and treatment barriers were assessed for correlation with demographic and clinical variables and analyzed by using the Chi-square test and logistic regression method using SPSS version 20.

Results Among 113 patients who sought help, treatment deficit was 85\% with patient factors contributing $76 \%$ predominantly affecting the unmarried group of patients. Common mental illnesses (CMIs) outnumbered severe mental illnesses (SMIs) of which anxiety spectrum disorder contributed the most. SMIs still appear to remain undiagnosed till late in the course of illness. Nicotine dependence was higher in males

Keywords

- determinants

- community mental health

- camp approach

- tribal

- India

- treatment gap $(p<0.001)$, and an increase in the dependence pattern was observed with increasing age $(p=0.001)$.

Conclusion Rising awareness and recognition of CMls as a common mental health concern while under-recognition of SMls among tribal communities needs further research. Considering attribution of symptoms to unknown factors, treatment barriers revolving around patient factors, and higher nicotine dependence in males, a timely evaluation of a multitargeted intervention to establish the balance in access to mental health care among the tribal population of Madhya Pradesh is warranted.
\end{abstract}

\section{Introduction}

Mental health is an important but underserved aspect of health in many developing countries including India. A recent mental health survey reported shocking figures of treatment gap in the mental health delivery system across

published online April 1, 2021
DOI https://doi.org/ $10.1055 / \mathrm{s}-0041-1723071$ ISSN 0976-3147. the country. ${ }^{1,2}$ Madhya Pradesh is the second largest state in India having a 7.2 million population and comprising of 51 districts located in the central part of India. ${ }^{3}$ The tribal population of India accounts for $8.6 \%$ of the total world's tribal population and has huge unmet needs for health, nutrition, and education. ${ }^{4}$ Also, the 2011 census shows

(C) 2021. Association for Helping Neurosurgical Sick People. This is an open access article published by Thieme under the terms of the Creative Commons Attribution-NonDerivative-NonCommercial-License, permitting copying and reproduction so long as the original work is given appropriate credit. Contents may not be used for commercial purposes, or adapted, remixed, transformed or built upon. (https://creativecommons.org/licenses/by-nc-nd/4.0/). Thieme Medical and Scientific Publishers Pvt. Ltd. A-12, 2nd Floor, Sector 2, Noida-201301 UP, India 
that the tribal population of Madhya Pradesh has seen a growth with $21.1 \%$ of the country's tribal population. ${ }^{5}$ Tribal population is more vulnerable to communicable and noncommunicable diseases due to deleterious beliefs about health and cultural practices. ${ }^{4}$ The inability to access health care services is linked to the emphasis by tribal communities on traditional healing practices and beliefs such as God's curse or God's wish etc. over contemporary and allopathic treatment. ${ }^{4}$ As per the figures of the National Mental Health Survey (NMHS), only 0.2 mental health professionals/lakh population and 0.05 psychiatrists/per 1 lakh population are available in the state of Madhya Pradesh, which is far less than the recommended national requirement of one psychiatrist per 1 lakh population. According to a recent study, Madhya Pradesh was ranked higher in Disability Adjusted Life Years for Idiopathic developmental Intellectual Disorders and conduct disorder among low sociodemographic index states ${ }^{6}$ while the treatment gap in Madhya Pradesh is found to be around 91\%.,7 The population of scheduled tribes in the district of Mandla is $57.2 \%{ }^{8}$ This highlights the severe inadequacy of mental health specialists in the state.

Mandla district is located in the Satpura hills. Situated 98.6 $\mathrm{km}$ away from Jabalpur, in the state of Madhya Pradesh of India. Mandla district has a population of 1,053,522 with a population density of 182 people per square kilometer as per census 2011. ${ }^{9}$ As per the latest statistics, Mandla district has eight community health centers, 34 primary health centers, 274 subcenters, one subdivisional hospital, and one district hospital. ${ }^{10}$ There are no psychiatrists in the public or private sector in Mandla district, and mental health care is provided by a single trained medical officer under National Mental Health Program with two to three staff nurses through "Mann-Kaksh" at Mandla district hospital. To the best of our knowledge, no inpatient facility is available in the area.

Such circumstances demand the assessment of factors that determine the mental health gap and develop mental health services to reach the underserved population. Reaching out to the community level through mental health camp appears to be a promising alternative. ${ }^{11}$ The assessment of mental health care needs and services in tribal districts through camp setting has not been widely studied in Madhya Pradesh so far. Therefore, a camp was conducted in a tribal district of Madhya Pradesh for providing mental health services and to find out the determinants of access to mental health care. This paper highlights the research findings from a health camp on various cultural determinants of mental health-seeking.

\section{Materials and Methods}

This is a cross-sectional study with face-to-face interviews inquiring into determinants of mental health problems among the tribal community of central India. The study was approved by the institutional ethics committee. The study is an excerpt from the health camp jointly organized by the institute in collaboration with one of the active nongovernmental organizations (Rotary International), the biggest public-private partnerships to reach the unreached in India. Along with the department of psychiatry, various clinical departments were independently associated with health camp for respective specialty needs in an underprivileged part of the tribal district of Madhya Pradesh.

The present study was conducted in Mandla town which is the administrative headquarters of Mandla district of Madhya Pradesh state in central India This mega health camp was organized at Mahatma Gandhi Ground in Mandla from November 7 to 14,2019 . The camp catered to the tribal population residing in remote pockets of the district and for people belonging to financially weaker sections.

Consecutive patients willing to give consent were interviewed on a semi-structured questionnaire independently by two psychiatrists on the campsite. A semi-structured interview questionnaire validated by three psychiatrists and public health experts was used. It consisted of demographic details such as age, gender, marital status, family income, religion, and residence. Clinical details included diagnosis as per international classification of diseases-10 (ICD-10), duration of illness, family history of mental illness, insight grades, attribution of symptoms, patient referral, treatment deficit, treatment barriers, expressed emotions, sexual dysfunction, comorbid medical diagnosis, and substance use. Treatment deficit was defined as the period between the inability to seek mental health care after the onset of symptoms and the first medical help among described pathways to care. Treatment barriers were defined in the form of patient factors, doctor factors, and treatment factors. Patient factors included awareness of being mentally ill, awareness about treatment options, cost of the treatment, and distance of mental health care facility from a residence. The doctor factor included the availability of psychiatrists or trained mental health professionals; inpatient mental health facility; and availability of services like electroconvulsive therapy, cognitive behavior therapy, etc. Treatment factors included the availability of medicine, the cost of medicine, the side effects of medicine, the route of administration, and the dosing regimen. Equivalence of expressed emotions (EEE) was measured by using 5-minute speech sample (FMSS) which takes 5 minutes to complete the assessments, a feasible alternative in a camp setting. ${ }^{12}$

A semi-structured interview, each of 10 minutes was conducted after the clinical consultation was over by alternate psychiatrists. In terms of sexual health, two specific leading questions were asked to check on sexual functioning, viz., (1) are you satisfied with your sexual performance? (2) Do you want to discuss any problem with sexual health?

Categorical variables like gender, psychiatric diagnosis, family history, treatment deficit, attribution of symptoms, expressed emotions equivalent, and substance use were analyzed by frequency and percentage method while continuous variables like age, duration of illness, and duration of untreated illness were analyzed by using mean and standard deviation. A Chi-square test was used to find a possible association between independent categorical variables with dependent outcome variables. Logistic regression analysis was performed to assess the determinants of 
treatment-seeking behavior. Odds ratio and 95\% confidence intervals were calculated. A $p<0.05$ was considered statistically significant. The information was collected by using preprinted forms and analyzed statistically after completion of the camp by using a licensed version of Statistical Package for Social Sciences- 17 .

\section{Results}

A total of 117 patients consulted mental health services in the camp of which four were found to have no mental health concerns and excluded from the statistical analysis. Out of 113 participants, most were aged above 30 years $(n=50$, $44.2 \%)$. Majority were males $(n=65,57.5 \%)$ and unmarried $(n=60,53.1 \%)$. Forty-two (37.2\%) participants were illiterate and the majority $(63,55.8 \%)$ belonged to the low-income group (-Table 1). The mean age of subjects was $32.9 \pm$ 3.4 years (standard deviation $=3.42$ ).

The majority of patients ( $n=76,67.3 \%$ ) were diagnosed with common mental illnesses, though psychotic spectrum disorders topped ( $n=28,24.8 \%)$ when an individual diagnosis was considered as listed in - Fig. 1. Twenty-four subjects (21.2\%) received dual diagnosis majority of which were comorbid intellectual developmental disabilities, seizure disorder, and neurodevelopmental disorders as shown in - Fig. 2. After excluding mental retardation and neurodevelopmental disorders, the median duration of illness was 72 months with a range from 1 to 359 months. Treatment deficit was present in 93 (82.3\%) subjects. The most common pathway for seeking medical help was primarily reported as attending general medical practitioners/registered medical practitioners in 68 (60.2\%) patients. Patient factors were the major barriers to treatment ( $n=86,76 \%$ ), while doctor factor $(n=14,12 \%)$ and treatment factor $(n=13,12 \%)$ were significantly lower in comparison. Maximum $(n=38,33.6 \%)$ patients attributed the symptoms to life events. The majority
( $n=44,38.9 \%$ ) of the study participants had insight grade-4, that is, the awareness of being ill with unknown attribution as per standardized grading of insight. ${ }^{13}$ The majority (81.4\%) of patients denied the questions on family history of mental illness. About substance use, approximately 48.7, 80.5, and $97.3 \%$ never consumed nicotine, alcohol, or cannabis, respectively. However, $32.7 \%$ had a dependence pattern of nicotine consumption. Only $9(8 \%)$ patients expressed concerns about sexual dysfunction while only 16 (14.2\%) patients had concomitant medical illness as shown in - Table 2.

Participants who did not avail of treatment regularly were found to be more associated with severe mental illness. Moreover, those who trusted the magico-religious method as the pathway for care were more associated with severe mental illness (-Table 3 ). EEE in the family were found in the following order: critical comments ( $n=31,27.4 \%)$, overinvolvement ( $n=15,13.3 \%)$, hostility ( $n=8,7.1 \%$ ), positive regards ( $n=8,7.1 \%)$, and warmth $(n=51,45.1 \%)$. Participants who received warmth and positive regard from their caregivers were more associated with common mental ailments. On the contrary, participants who received hostility from caregivers were more associated with severe mental illness (-Table 3). Prescribed treatment during camp included prescription of antidepressants ( $n=47,41 \%$ ), antipsychotics ( $n=32,28 \%$ ), benzodiazepines $(n=10,8.6 \%$ ), mood stabilizers ( $n=9,8 \%$ ), and other adjuvant medications ( $n=30,26 \%$ ).

Using logistic regression, it was observed that SMI are more likely to be diagnosed with advancing age $(p=0.021)$. Using multinomial logistic regression, we looked at various determinants of treatment-seeking with (treatment barrier*marital status), (lifetime nicotine consumption*gender), (dependence nicotine*gender), and (dependence nicotine*age) respectively, as shown in -Table 4. Marital status was found to be a significant predictor of treatment barrier. Out of 60 unmarried participants, 52 had "patient factors" as treatment barriers which were comparatively low

Table 1 Demographic details

\begin{tabular}{|c|c|c|c|c|}
\hline S. no. & Category & Subcategory & Frequency & Percentage (\%) \\
\hline \multirow[t]{3}{*}{1.} & \multirow[t]{3}{*}{ Age } & 18 years or less & 27 & 23.9 \\
\hline & & Between 19 and 30 years & 36 & 31.9 \\
\hline & & Above 30 years & 50 & 44.2 \\
\hline \multirow[t]{2}{*}{2.} & \multirow[t]{2}{*}{ Gender } & Male & 65 & 57.5 \\
\hline & & Female & 48 & 42.5 \\
\hline \multirow[t]{2}{*}{3.} & \multirow[t]{2}{*}{ Marital status } & Unmarried & 60 & 53.1 \\
\hline & & Married & 53 & 46.9 \\
\hline \multirow[t]{5}{*}{4.} & \multirow[t]{5}{*}{ Education } & Illiterate & 42 & 37.2 \\
\hline & & Primary & 35 & 31.0 \\
\hline & & Secondary & 20 & 17.7 \\
\hline & & Higher secondary & 6 & 05.3 \\
\hline & & Graduate & 10 & 08.8 \\
\hline \multirow[t]{3}{*}{5.} & \multirow[t]{3}{*}{ Income ${ }^{\mathrm{a}}$} & Low & 63 & 55.8 \\
\hline & & Lower middle & 49 & 43.4 \\
\hline & & Upper middle & 01 & 00.8 \\
\hline
\end{tabular}

ancome as per modified Kuppuswamy classification. ${ }^{32}$ 


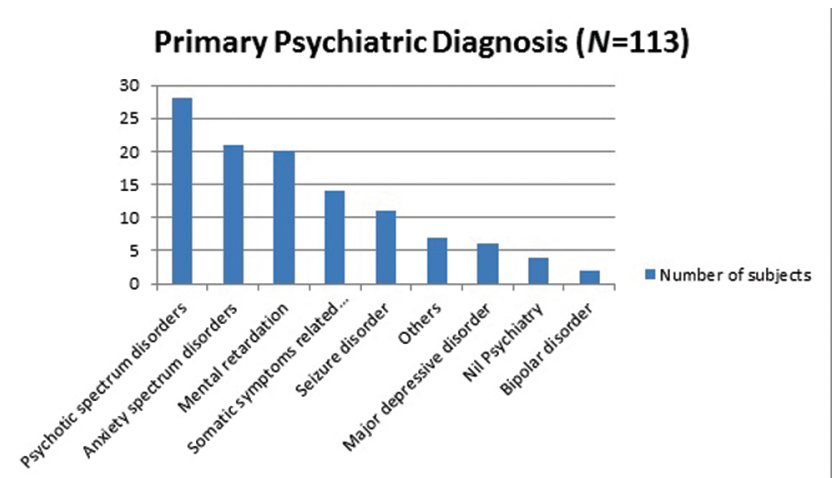

Fig. 1 Primary psychiatric diagnosis received by patients.

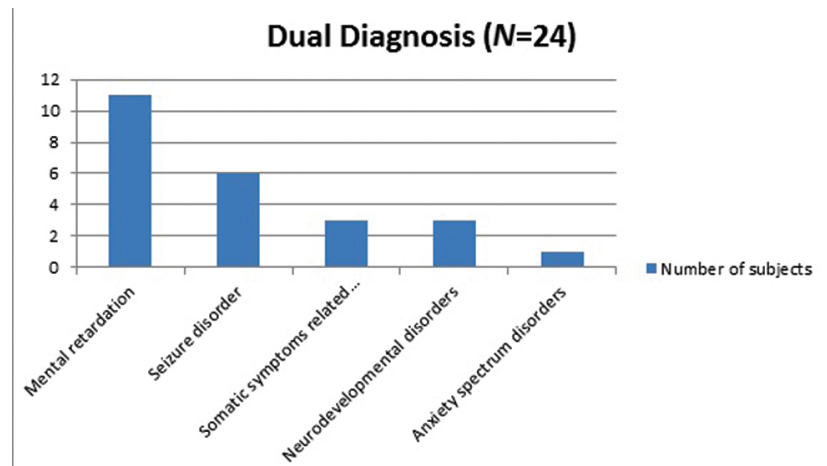

Fig. 2 Additional diagnosis received by the patients in addition to primary diagnosis.

in the married group. Those who were unmarried were most affected by the patient factors associated with the treatment barrier. We compared each treatment barrier group against the reference category of "patient factors." In comparison between those who have "patient factors" as treatment barriers and those who have "medicinal factors" as treatment barriers, "marital status" was a significant predictor.

In terms of nicotine consumption (nil and lifetime) versus gender, a greater number of males consumed nicotine during their lifetime as compared with females. We compared each nicotine consuming participant group against the reference category of "never consuming nicotine." In comparison between those who have "never consumed nicotine" and those who have "consumed nicotine during their lifetime," "gender" was a significant predictor. Out of 48 participants who were females, 34 had never consumed nicotine in comparison to males. Four females out of 48 , consumed nicotine during their lifetime in comparison to 10 males out of 65 .

In terms of nicotine consumption (nil and dependence) versus gender and age, males showed a more dependence pattern of nicotine consumption. Also, there was an association between more dependence on nicotine consumption with increasing age. The independent variables, which were significant predictors in the model, were again gender $(p=0.000)$ and age $(p=0.001)$. We compared each nicotine consuming participant group against the reference category of "never consuming nicotine." In comparison between those who have "never consumed nicotine" and those who have "dependence pattern of nicotine consumption," "gender" was a significant predictor $(p=0.001)$. Out of 48 participants who were females, eight have a dependence pattern of nicotine consumption. However, this share was comparatively higher in the males' group. Out of 65 participants who were males, 29 have a dependence pattern of nicotine consumption. Out of 63 participants who were aged 30 years or less, eight respondents have a dependence pattern of nicotine consumption as compared with 50 participants who were aged above 30 years, 29 have a dependence pattern of nicotine consumption.

\section{Discussion}

The results of the study appear to be unique in terms of approach to an unserviced population through a camp setting to look out for the determinants of tribal mental health care. So far medical issues barring mental health have been studied across different states of India, but this study in our knowledge is one of the first studies reporting concerns related to tribal mental health. ${ }^{14-17}$ The observation says SMIs were associated more with increasing age reflects that severe mental illnesses remain undiagnosed till late in contrary to CMIs among the tribal population. This may be due to the inability of tribal patients to be aware of the SMI, unawareness of treatment availability, reliance on magico-religious or other cultural models of healing, cost of the treatment, and social stigma associated with it. In terms of global mental health burden, India contributes approximately $14 \%$, with differences within service utilization patterns across various Indian states. ${ }^{6}$ The state of Madhya Pradesh has a treatment gap of $91 \%$ for all the mental health problems in toto, ${ }^{7}$ which was measured in terms of treatment deficit as $82 \%$ in the current tribal camp setting. Since two-thirds of subjects were literate explains the higher motivation to reach out to camp and literacy appears promising in terms of mental health care seeking ${ }^{18}$; however, no statistical association of insight with literacy could be found. Also, two-thirds of the subjects had CMIs which bring up an interesting fact of rising awareness and recognition of CMIs as a common mental health concern among tribal population. ${ }^{19}$ Only one-fifth of subjects were able to recall the positive family history could be secondary to a lack of awareness or overinclusive attitude among tribal families about understanding the dimensions of stress and mental health. This could also be due to memory bias of subjects or underreporting secondary to the stigma which requires further research. In terms of pathways to care (before reaching out to a camp), study findings indicate that three-fifths of the subjects were seeking treatment from physicians available in the locality and were referred to camp for the management of mental health issues. An important finding of the study brings us to think about a shift from provider-centric to the user-centric model of mental health care in rural India. ${ }^{20}$ Although a user-centric attitude could be an important indicator of service delivery, the correct balance between the service provider and service user should be kept in mind. Strengthening and capacity building of the primary 
Table 2 Clinical details

\begin{tabular}{|c|c|c|c|c|}
\hline S. no. & Category & Subcategory & Frequency & Percentage (\%) \\
\hline \multirow[t]{2}{*}{1.} & \multirow[t]{2}{*}{ Diagnosis } & Common mental illness & 76 & 67.3 \\
\hline & & Severe mental illness & 37 & 32.7 \\
\hline \multirow[t]{2}{*}{2.} & \multirow[t]{2}{*}{ Treatment deficit } & Present & 93 & 82.3 \\
\hline & & Absent & 20 & 17.7 \\
\hline \multirow[t]{4}{*}{3.} & \multirow[t]{4}{*}{ Pathway to care } & Physician & 68 & 60.2 \\
\hline & & Magico-religious therapy & 18 & 15.9 \\
\hline & & Nonpsychiatric physician & 09 & 08.8 \\
\hline & & Psychiatrist & 18 & 15.9 \\
\hline \multirow[t]{3}{*}{4.} & \multirow[t]{3}{*}{ Treatment barrier } & Patient factors & 86 & 76.1 \\
\hline & & Doctor factors & 14 & 12.4 \\
\hline & & treatment factors & 13 & 11.5 \\
\hline \multirow[t]{7}{*}{5.} & \multirow[t]{7}{*}{ Attribution of symptoms } & Life event & 38 & 33.6 \\
\hline & & Evil spirit & 01 & 00.9 \\
\hline & & Karma & 06 & 05.3 \\
\hline & & Physical illness & 37 & 32.7 \\
\hline & & Other religious factor & 13 & 11.5 \\
\hline & & Death of unknown person & 06 & 05.3 \\
\hline & & $\begin{array}{l}\text { Others beliefs related to diet, allergy, } \\
\text { etc. }\end{array}$ & 12 & 10.6 \\
\hline \multirow[t]{6}{*}{6.} & \multirow[t]{6}{*}{ Insight to illness } & $\begin{array}{l}\text { Awareness that one is ill-unknown } \\
\text { attribution }\end{array}$ & 44 & 38.9 \\
\hline & & $\begin{array}{l}\text { Awareness that one is ill-wrong } \\
\text { attribution }\end{array}$ & 19 & 16.8 \\
\hline & & Slight awareness & 18 & 15.9 \\
\hline & & Complete denial & 13 & 11.5 \\
\hline & & Intellectual insight & 13 & 11.5 \\
\hline & & Emotional insight & 06 & 05.3 \\
\hline \multirow[t]{5}{*}{7.} & \multirow[t]{5}{*}{ Expressed emotion equivalent } & Warmth & 51 & 45.1 \\
\hline & & Hostility & 08 & 07.1 \\
\hline & & Emotional over involvement & 15 & 13.3 \\
\hline & & Critical comments & 31 & 27.4 \\
\hline & & Positive regards & 08 & 07.1 \\
\hline \multirow[t]{3}{*}{8.} & \multirow[t]{3}{*}{ Family history } & Nil & 92 & 81.4 \\
\hline & & First degree relative & 18 & 15.9 \\
\hline & & Second degree relative & 03 & 02.7 \\
\hline \multirow[t]{4}{*}{9.} & \multirow[t]{4}{*}{ Nicotine use } & Nil & 55 & 48.7 \\
\hline & & Lifetime & 14 & 12.4 \\
\hline & & Harmful use & 07 & 06.2 \\
\hline & & Dependence pattern & 37 & 32.7 \\
\hline \multirow[t]{4}{*}{10.} & \multirow[t]{4}{*}{ Alcohol use } & Nil & 91 & 80.5 \\
\hline & & Lifetime & 15 & 13.3 \\
\hline & & Harmful use & 05 & 04.4 \\
\hline & & Dependence pattern & 02 & 01.8 \\
\hline \multirow[t]{4}{*}{11.} & \multirow[t]{4}{*}{ Cannabis use } & Nil & 110 & 97.3 \\
\hline & & Lifetime & 01 & 00.9 \\
\hline & & Harmful use & 00 & 00.0 \\
\hline & & Dependence pattern & 02 & 01.8 \\
\hline
\end{tabular}


Table 2 (continued)

\begin{tabular}{|l|l|l|l|l|}
\hline S. no. & Category & Subcategory & Frequency & Percentage (\%) \\
\hline \multirow{2}{*}{12.} & \multirow{2}{*}{ Sexual dysfunction } & Present & 09 & 08.0 \\
\cline { 3 - 5 } & & Absent & 104 & 92.0 \\
\hline \multirow{2}{*}{13.} & Medical illness & Present & 16 & 14.2 \\
\cline { 3 - 5 } & & Absent & 97 & 85.8 \\
\hline
\end{tabular}

Table 3 Association of treatment deficit, pathways to care and expressed emotion equivalent with diagnosis

\begin{tabular}{|l|l|l|l|l|}
\hline S. no. & Variables & Chi-square & Standard error & Significance \\
\hline 1. & Treatment deficit* diagnosis & 3.474 & 0.077 & 0.05 \\
\hline 2. & Pathway to care* diagnosis & 9.457 & 0.094 & 0.02 \\
\hline 3. & EEE* diagnosis & 10.368 & 0.091 & 0.03 \\
\hline
\end{tabular}

Abbreviation: EEE, expressed emotion equivalent.

Note: "indicates association with.

Table 4 Correlation of demographic and clinical variables that were significant

\begin{tabular}{|c|c|c|c|c|c|}
\hline & \multirow[t]{2}{*}{ Parameters } & \multicolumn{4}{|c|}{ Binary logistic regression } \\
\hline & & Log odds & SE & $95 \% \mathrm{Cl}$ & Significance \\
\hline \multirow[t]{3}{*}{1} & Diagnosis*age & 0.040 & 0.017 & $1.006-1.077$ & 0.021 \\
\hline & & \multicolumn{4}{|c|}{ Multinomial logistic regression } \\
\hline & & B & Significance & $\operatorname{Exp}(B)$ & LR significance \\
\hline 2 & Treatment barrier* marital status & 2.295 & 0.014 & 9.923 & 0.012 \\
\hline 3 & $\begin{array}{l}\text { Lifetime nicotine } \\
\text { consumption* gender }\end{array}$ & 1.489 & 0.049 & 4.431 & 0.001 \\
\hline 4 & $\begin{array}{l}\text { Dependence nicotine } \\
\text { consumption* gender }\end{array}$ & 2.486 & 0.000 & 12.007 & 0.001 \\
\hline 5 & $\begin{array}{l}\text { Dependence nicotine } \\
\text { consumption*age }\end{array}$ & 0.085 & 0.001 & 1.089 & 0.001 \\
\hline
\end{tabular}

Abbreviations: $\mathrm{Cl}$, confidence interval; LR, likelihood ratio; SE, standard error.

Note: *indicates correlation with.

health care system through DMHP involving private-public partnership may improve the quality of service delivery and follow-up care given existing inequalities to mental health care access. ${ }^{21,22}$ The other way to look at it is reducing the treatment gap by strengthening the undergraduate medical syllabus, emphasizing mental health treatment as a separate domain to be efficient enough to address CMI in rural and tribal communities. ${ }^{23}$ The most common and significant findings from the study included barriers faced by patients seeking treatment before reaching out to a camp accounting for wider treatment deficit; an indicator measured in terms of treatment barriers divided into doctor factor, medical factor, and patient factor in the current study. Patient factors contributed nearly three-fourths of the barriers as compared with medicinal and doctor factors. This allows us to explore the deficits of existing service delivery and possible ways of generating awareness about identifying and seeking treatment for mental health problems among tribal Indians as reported in a similar study in the same state, but a different region of Madhya Pradesh. ${ }^{24,25}$ Despite a lack of awareness about dimensions of mental health, most of the subjects were able to accept their illness but with different attributions as depicted under insight to illness in - Table 2 . The most common attribution was found to be significant life events and physical illness. Findings of associated hostility among caregivers of SMIs and warmth and positive regards among caregivers of CMIs is consistent with the earlier finding, ${ }^{26}$ but this study being in a camp setting has limitations in terms of assessment of EEE through FMSS. This study probably was unique in terms of checking sexual functioning in a camp setting; as many cases go unnoticed due to the stigma associated with it. Surprisingly, $8 \%$ of males responded "yes" to one of the questions though actual figures might be higher. ${ }^{27}$ Lack of privacy during the interview, perceived devaluation by others and fear of sexual health could be reasons for low rates that require further research. Lower rates of concurrent medical illness could be due to a relatively healthy lifestyle of rural Indians or unawareness and inaccessibility to routine health checkups. History of poor compliance and relying on magico-religious therapies predominated among SMIs, consistent with earlier findings. ${ }^{28}$ According to the NMHS report, the median interval between onset of illness and consultation in Madhya Pradesh was found to be 1 year, at least two health care providers were consulted by the patient for mental health concerns, and almost 
two-thirds of the times the consulted doctor was from the public sector. ${ }^{11}$ The study also emphasized that the majority of the patients admitted to seeking mental health care were found to be involved in magico-religious therapy from temples, dargah, local priest, or traditional healer, and the main reasons cited for not seeking advice from the professionals were lack of mental health services, costly treatment, distant hospitals, and unawareness of availability of treatment. The unmarried subjects were the most affected by patient factor could explain the role of family support in terms of affection and financial bearing. ${ }^{29}$ Males outnumbering females in exposure to nicotine is consistent with earlier studies; however, association of increase in the nicotine dependence with increasing age requires further research. ${ }^{29}$

Study findings from the camp are significant with limited generalizability due to the small sample size, conducted in a single tribal district of Madhya Pradesh, and lack of use of validated tools. Nonetheless, these findings highlight the rising awareness about mental illnesses, but on the other hand reflect significant treatment deficits in tribal areas as evaluated across recent reports. ${ }^{30,31}$ Timely steps should be taken in underserviced areas of Madhya Pradesh and possibly similar in other states, where the tribal population has limited access to health care as highlighted in NMHS report. ${ }^{1}$ We need to consider multitargeted intervention strategies to deliver services that are directed specifically to the tribal population by using existing resources. ${ }^{7}$ Innovative medical models to strengthen tribal health infrastructure are currently in the pipeline to be considered by policymakers. ${ }^{4}$ To conclude, we feel that client-centered services should be emphasized in upcoming policies and programs to cater to the unmet mental health care needs of the tribal population.

\section{Authors' Contributions}

R.S. and S.D. are primarily responsible for designing and data collection of the study. R.S. and A.L. have contributed to the data analysis. R.S., P.S., and A.R. have contributed to manuscript writing and proof reading.

\section{Funding \\ None.}

\section{Conflict of Interest}

None declared.

\section{References}

1 Murthy RS. National mental health survey of India 2015-2016. Indian J Psychiatry 2017;59(1):21-26

2 Gururaj GMV, Benegal V, et al. National Mental Health Survey of India, 2015-16: Prevalence, Pattern and Outcomes. Available at: http://indianmhs.nimhans.ac.in/Docs/Report2.pdf.

3 Bose A. Census of India, 2011. Econ Polit Wkly. Available at: https://www.epw.in/journal/2011/04/letters/census-india-2011. html.

4 Kumar MM, Pathak VK, Ruikar M. Tribal population in India: a public health challenge and road to future. J Family Med Prim Care 2020;9(2):508-512
5 Census of India. Demography of scheduled tribes. Off Regist Gen Gov India. Published online 2011:347-440. Available at: http://censusmp.nic.in/censusmp/Data/PCA_DATA/008 Chapter - 6-ST .pdf

6 Sagar R, Dandona R, Gururaj G, et al; India State-Level Disease Burden Initiative Mental Disorders Collaborators. The burden of mental disorders across the states of India: the Global Burden of Disease Study 1990-2017. Lancet Psychiatry 2020;7(2):148-161

7 Kokane A, Pakhare A, Gururaj G, et al. Mental health issues in Madhya Pradesh: insights from National Mental Health Survey of India 2016. Healthcare (Basel) 2019;7(2):E53

8 Census of India. Coimbatore, Tamilnadu: Dist census handbook; Available at: https://censusindia.gov.in/2011census/ dchb/3331_PART_B_DCHB_COIMBATORE.pdf. Accessed 2011

9 Census Organisation of India. Chapter-2: Population Composition. Census 2011. Available at: https://censusindia. gov.in/2011Census/pes/Pesreport.pdf. Accessed 2012

10 Government of India Ministry of Health and Family Welfare Statistics Division. Rural Health Statistics. Published 2018. Available at: https://main.mohfw.gov.in/sites/default/files/ Final RHS 2018-19_0.pdf. Accessed August 6, 2020

11 Thara R, Padmavati R, Aynkran JR, John S. Community mental health in India: a rethink. Int J Ment Health Syst 2008;2(1):11

12 Magaña AB, Goldstein JM, Karno M, Miklowitz DJ, Jenkins J, Falloon IR. A brief method for assessing expressed emotion in relatives of psychiatric patients. Psychiatry Res 1986;17(3):203-212

13 Hodo DW, Kaplan and Sadock's synopsis of psychiatry: behavioral sciences/clinical psychiatry. JAMA J Am Med Assoc. doi:10.1001/jama.1996.03530350065041 2003

14 Mahapatro M, Issues AK-HPP, Health seeking behaviour in a tribal setting. DOI: 10.31901/24566799.2018/17.1-2.4132000

15 Jacob I. Title: health and health seeking behaviour among tribal communities in india: a socio-cultural perspective accessed on. Vol 2.; 2014. Available at: https://papers.ssrn.com/sol3/ papers.cfm?abstract_id=3151399. Accessed August 11, 2020

16 Rao V, Bhat J, Yadav R, Muniyandi M, Sharma R, Bhondeley M K. Pulmonary tuberculosis: a health problem amongst Saharia tribe in Madhya Pradesh. Available at: https://www.ncbi.nlm. nih.gov/pmc/articles/pmc4510762/. Accessed August 11, 2020.

17 GhoshK,ColahRB,MukherjeeMB.Haemoglobinopathiesintribal populations of India. Indian J Med Res 2015;141(5):505-508

18 Kutcher S, Wei Y, Coniglio C. Mental health literacy: past, present, and future. Can J Psychiatry 2016;61(3):154-158

19 Arvind BA, Gururaj G, Loganathan S, et al; NMHS collaborators group. Prevalence and socioeconomic impact of depressive disorders in India: multisite population-based cross-sectional study. BMJ Open 2019;9(6):e027250

20 Samudre S, Shidhaye R, Ahuja S, et al. Service user involvement for mental health system strengthening in India: a qualitative study. BMC Psychiatry 2016;16:269

21 Garg K, Kumar CN, Chandra PS. Number of psychiatrists in India: baby steps forward, but a long way to go. Indian J Psychiatry 2019;61(1):104-105

22 Gupta S, Sagar R. National mental health programme-optimism and caution: a narrative review. Indian $\mathrm{J}$ Psychol Med 2018;40(6):509-516

23 Singh OP. Closing treatment gap of mental disorders in India: opportunity in new competency-based Medical Council of India curriculum. Indian J Psychiatry 2018;60(4):375-376

24 Shidhaye R, Raja A, Shrivastava S, Murhar V, Ramaswamy R, Patel V. Challenges for transformation: a situational analysis of mental health care services in Sehore District, Madhya Pradesh. Community Ment Health J 2015;51(8):903-912 
25 Shidhaye R, Shrivastava S, Murhar V, et al. Development and piloting of a plan for integrating mental health in primary care in Sehore district, Madhya Pradesh, India. Br J Psychiatry 2016;208, Suppl 56):s13-s20

26 Sadath A, Kumar R, Karlsson M. Expressed emotion research in India: a narrative review. Indian J Psychol Med 2019;41(1):18-26

27 Avasthi A, Grover S, Sathyanarayana Rao TS. Clinical practice guidelines for management of sexual dysfunction. Indian J Psychiatry 2017;59(Suppl 1):S91-S115

28 MullaS, AnsariS. Analysis of variables affecting drug compliance in schizophrenia. Ind Psychiatry J 10.4103/0972-6748.144968
29 Ponnuchamy L, Mathew BK, Mathew S, Udayakumar GS, Kalyanasundaram S, Ramprasad D. Family support group in psychosocial rehabilitation. Indian J Psychiatry 2005;47(3):160-163

30 Narain JP. Health of tribal populations in India: how long can we afford to neglect? Indian J Med Res 2019;149(3):313-316

31 Mavalankar D. Doctors for tribal areas: issues and solutions. Indian J Community Med 2016;41(3):172-176

32 Wani RT. Socioeconomic status scales-modified Kuppuswamy and Udai Pareekh's scale updated for 2019. J Family Med Prim Care 2019;8(6):1846-1849 